\title{
Entrevista con la Mtra. Irma Charlotte Carranza Juárez (IC), ganadora del premio nacional al Fomento de la Lectura México Lee 2012.
}

Por Juan Pablo Martínez López (JP)

Antes de iniciar la conversación con nuestra invitada, daré un esbozo de su trayectoria: ella es Ingeniera en Computación, cursó diferentes diplomados en Creación literaria, en profesionalización de mediadores de Salas de lectura, tiene un diplomado en multimedia; es fundadora del Centro cultural La Tercera Luna, organismo dedicado a la promoción de la lectura y escritura; ha participado en diversos congresos nacionales e internacionales de escritores y promotores de lectura y escritura; además ha publicado varios libros.

JP: ¿Qué nos puede decir del premio al fomento de la lectura México Lee 2012?

IC: Este premio es importante debido a que permite promover la lectura creando más espacios a nivel nacional por medio del Programa Nacional de Salas de Lectura y su Misión.

JP: ¿Cuáles podrían ser las características más importantes del proyecto?

IC: Este proyecto es una iniciativa de CONACULTA, y la finalidad es abrir espacios donde se creen comunidades lectoras que tengan la posibilidad de leer de una manera libre, gratuita e inclusiva, en los que se le proporcione a la gente los medios y los acervos de libros para que puedan realizar esta actividad guiados por un mediador especializado que les ayude a desarrollar su proceso lector.

JP: ¿Qué habilidades pretende desarrollar el
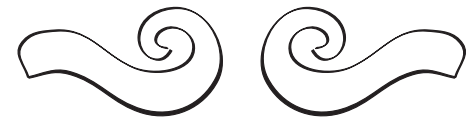

proyecto de Salas de lectura, en las personas no-lectoras?

IC: Pretendemos desarrollar un proceso lector, es decir que a través de leer y comentar con otras personas los libros, puedan desarrollar un pensamiento crítico. Teniendo a la mano un acervo adecuado y con esto desarrollar un proceso lector y además mejorar sus habilidades académicas, encontrar disfrute en la lectura y convertirse en comunidades lectoras.

JP: ¿Cómo fue su inicio en el programa, cuáles fueron sus bases?

IC: Influyen varias cosas, una muy importante es el hecho de que me he dedicado a escribir y publicar libros, uno de ellos para niños que ha sido leído en varias escuelas, este libro fue pretexto para hablar con los niños de asuntos que a ellos les importan.

Yo veía que a partir de este libro, los niños podían acercarse a la lectura, esto fue importante para mí, y me pareció necesario saber más sobre cómo fomentar la lectura no sólo entre los niños sino entre cualquier público. También influyeron en mí diversos autores que hablan de lo que significa la lectura.

JP: ¿Cómo influye el proyecto para que las personas tengan evolución en sus procesos lectores?

1 Séptimo semestre de la licenciatura en Ciencias de la Comunicación. (enfermosdepachuca@hotmail.com) 
IC: Poniendo al alcance los acervos de libros que proporciona Conaculta. Se tiene un acervo base que se puede ampliar de acuerdo a las necesidades del público que asiste y yo como mediadora busco ampliarlo en forma adecuada, ya que los mediadores también somos gestores de lo necesario para que funcione la Sala de Lectura.

JP: Existe un problema de mercado, los precios tan altos que existen en muchos libros, ¿Cómo entra el proyecto de fomento a la lectura, en este problema?

IC: Se habla de que le gente no lee porque los libros son caros, ahí lo que yo aplico en mis Salas de Lectura es buscar libros en ediciones económicas para ampliar nuestras lecturas. Hay posibilidades de buscar en ferias de libros, en remates, en editoriales económicas.

También es importante observar a qué le damos valor, muchas veces preferimos gastar el dinero en diversiones caras antes que hacerlo en libros y pretendemos que la cultura sea gratuita. Así es difícil valorar la cultura en general.

JP: ¿Cómo se puede educar a profesores nolectores para que se involucren en el proyecto?

IC: Yo creo que una forma es aplicando lo que estamos haciendo nosotros en Salas de Lectura que sería hacer círculos de lectura entre los profesores, aunque a veces pasa que los maestros están muy cargados de trabajo y no tienen tiempo, pero es difícil transmitir el gusto por la lectura si no se lee, por lo que creo que sería importante buscar en las escuelas que los maestros tuvieran ese espacio de lectura. Esa es mi idea, pero las escuelas a distintos niveles podrían plantear sus estrategias.
JP: ¿Usted cree que existe un fomento a la lectura en procesos formativos, y en programas educativos?

IC: En ciertos niveles sí existe, las herramientas se tienen, lo que se trabaja en las Salas de Lectura son herramientas sencillas, además de usar dinámicas sobre la lectura para que ésta pueda ser lúdica, incluyendo la creación literaria derivada de las lecturas. Todo esto para que se vea al libro y la escritura como algo que va más allá del proceso educativo y puede ser parte de la vida personal.

JP: ¿Cuál cree que sea la raíz del problema de la falta de lectura en México?

IC: Parte fundamental son los medios: la televisión y la radio, ellos nos obligan a comprar y nos hacen ver lo que aparentemente es "importante"; en todo esto no entra la lectura.

Otro problema es la elección de las lecturas, en ciertos momentos se necesita una guía para empezar a leer y seguir con gusto por los textos.

JP: Muchas gracias por la entrevista.

La entrevista se llevó a cabo en el foro de Radio y Televisión de la Universidad La Salle Pachu$\mathrm{ca}$, concluye con la entrega de constancia y agradecimiento a la Mtra. Charlotte por parte de la Dra. Esther Fragoso ${ }^{2}$.

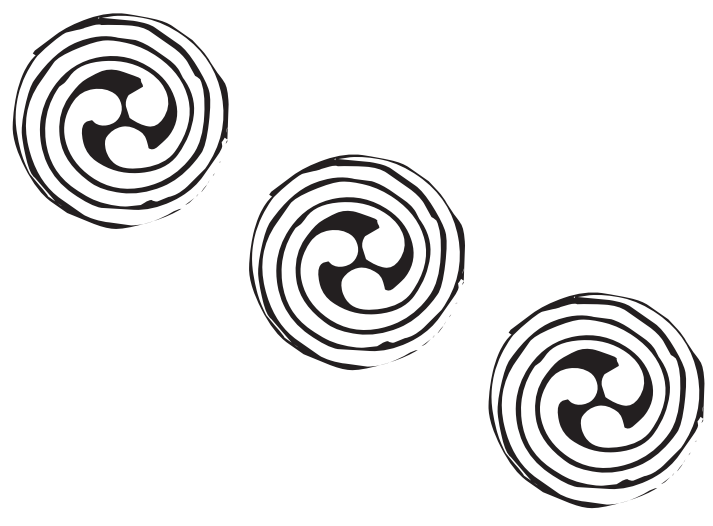

2 Directora de la revista Huella de la Palabra 